\title{
Free allocation rules in the EU Emissions Trading System: what does the empirical literature show?
}

\author{
Verde, S a.; Teixidó, J. b; Marcantonini, C. a; Labandeira, X. ${ }^{\text {c }}$ \\ a- European University Institute, Florence School of Regulation-Climate \\ b- Universitat de Barcelona, Dept. of Econometrics, Statistics and Applied Economics- Public Policies. \\ c- Universidade de Vigo \& Economics for Energy.
}

\begin{abstract}
This paper analyses the rules for free allocation in the EU Emissions Trading System (EU ETS). The analysis draws on the empirical evidence emerging from two literature strands. One group of studies sheds light on the following questions: how efficient are free allocation rules in minimizing the risk of carbon leakage? Have they become more efficient over the trading periods? What are the technical limits to making them more efficient? Further: is firm behaviour neutral to allowance allocation? Did specific provisions induce strategic behaviour with unintended effects? Studies from the second group estimate sectoral pass-through rates for the costs imposed by the EU ETS. Taking cost pass-through into account is necessary for properly targeting free allocation. The difficulty of accurately quantifying sectoral differences in cost pass-through ability is the main obstacle to achieving further efficiency in allowance allocation. The new rules defined in the reform for Phase IV (2021-2030) make some progress in this direction nevertheless. In any case, with carbon prices expected to rise and the total volume of allowances shrinking, free allocation - however efficient may it be - cannot be the only or main measure for preventing carbon leakage in the future.
\end{abstract}

\section{Introduction}

Since 2005, the EU Emissions Trading System (EU ETS) has been the EU's prime instrument for decarbonising the economy. It caps overall emissions of carbon dioxide, nitrous oxide and perfluorocarbons from over 11,000 heavy energy-using and electricity generating installations and aircraft, covering about $45 \%$ of the EU's greenhouse gas (GHG) emissions. Still today, it remains the world's largest cap-and-trade system regulating GHG emissions at the installation level. The EU ETS is approaching the end of its third trading period, which is called Phase III (2013-2020). It will then enter Phase IV (2021-2030) under a newly-revised legislation. The rules governing the allocation of emission allowances are a fundamental component of the system's regulation. They have changed significantly across the trading periods as part of wider reforms, including the latest reform for Phase IV.

In a cap-and-trade system such as the EU ETS, emission allowances can be distributed to installations by free allocation, through auctions, or a mix of these two allocation methods. In the last case, which is the most common among the systems extending beyond the electricity sector, the rules for free allocation constitute an area of special interest. The reasons are 
twofold. First, free allocation rules can have equity implications related to the distribution of scarcity rents (the economic value created by limited supply of emission allowances relative to demand) between consumers and producers as well as among the latter. Second, given different carbon prices across the world and international competition, the rules can have implications for the competitiveness of regulated sectors and ultimately for the environmental effectiveness of the system in reducing global GHG emissions. In climate economics and policy, the displacement of GHG emissions due to differences in the stringency of mitigation policies is called "carbon leakage". Minimising the risk of market share losses to foreign competitors and, thereby, minimising the risk of carbon leakage, is the economic rationale for giving allowances for free.

Crucially, giving allowances away is similar but not equivalent to granting tax exemptions. Since they have market value, using preallocated allowances for compliance carries an opportunity cost, equal to the revenue that would be earned if (the corresponding emissions were avoided and) the allowances were sold. It is therefore legitimate to expect that rational profit-maximising firms will factor such opportunity costs in their decisions - as they would with real costs. Building on the Coase Theorem (Coase, 1960), the assumption that regulated firms take opportunity costs into account, and several other neoclassical assumptions about markets (both the allowance market and the output markets) and firm behaviour, underlie the "independence property" of cap-and-trade systems (Hahn and Stavins, 2011). The essence of the independence property is that the overall emission target is achieved at minimum cost irrespective of how the allowances are initially distributed. Economists, while emphasising the independence property, tend to focus more on its possible violations, and less on distributional implications. Nevertheless, the reality of cap-and-trade systems highlights the political relevance of the second.

This paper analyses the rules for free allocation in the EU ETS with a view to establishing whether, how, and why they may have deviated from an ideal setting that reconciles efficiency and equity considerations. The analysis draws on the empirical evidence emerging from two distinct strands of the EU ETS literature. One group of studies, directly concerned with these rules, sheds light on the following questions: how efficient are free allocation rules in minimising the risk of carbon leakage? Have they become more efficient over the trading periods? What are the technical limits to making them more efficient? Further: is firm behaviour neutral to allowance allocation (consistent with the independence property)? Did specific provisions induce strategic behaviour with unintended effects? Studies from the second group more specifically estimate sectoral pass-through rates for the costs imposed by 
the EU ETS. From a regulatory perspective, taking cost pass-through into account is necessary for properly targeting free allocation, be it primarily for the purpose of minimising "windfall profits" or of minimising the risk of carbon leakage. Thus, reviewing the literature on cost passthrough allows us to better assess how the allocation rules in operation deviate from perfect efficiency.

Windfall profits are controversial because they entail a wealth transfer from consumers to producers that is difficult to justify, raising equity issues. We focus on windfall profits from pass-through of opportunity costs, but there are other ways in which firms can profit from participation in the EU ETS ${ }^{1}$. Depending on different factors, including notably the degree of international competition and abatement possibilities, it is possible for some firms to increase profits by passing through the opportunity cost of free allowances onto output prices. Therefore, the quantity of free allowances granted to a firm should be inversely related to its ability to pass through the costs of regulation (Vollebergh et al., 1997; Bovenberg and Goulder, 2000; Quirion, 2003). In practice, precise estimates of cost pass-through ability are difficult to derive, especially in manufacturing sectors. Proxies can, and indeed are, used instead. As far as the EU ETS is concerned, equity issues related to windfall profits were much more relevant in the first two trading periods, when over $90 \%$ of allowances were distributed for free. Under the current allocation regime and with the volume of free allowances progressively shrinking, well-targeted allocations are increasingly important for minimising the risk of carbon leakage.

The rest of the paper is organised as follows. Section 2 describes the evolution of allowance allocation through the trading periods; Section 3 reviews the empirical literature assessing free allocation rules; Section 4 reviews the literature estimating cost pass-through rates. Section 5 concludes.

\section{The evolution of allowance allocation through the trading periods}

In the EU ETS, free allocation rules have significantly changed over the trading periods. To understand the empirical literature analysing these rules, one needs to know how allowance allocation and the relevant legislation have evolved.

Both in Phase I (2005-2007) and Phase II (2008-2012), "grandfathering” was the basic allocation regime. That is, almost all allowances were distributed free in proportion to

\footnotetext{
${ }^{1}$ The literature identifies four types of windfall profits under the EU ETS: a) from pass-through of opportunity costs; b) from overallocation; c) from exploiting the price differential between emission offsets issued under the Kyoto Protocol's flexible mechanisms and emission allowances issued under the EU ETS (de Bruyn et al., 2016); and d) from inframarginal rents, arising when marginal producers setting output market prices use more carbonintensive technologies.
} 
installations' historical emissions. A fundamentally different allocation system was subsequently adopted. Since Phase III, electricity generation has ceased to receive free allowances (with exceptions for some countries) upon clear evidence of high cost pass-through and related windfall profits. For all other sectors, targeted free allocation has been applied. The current regime of free allocation hinges on: a) the distinction between the sectors "deemed at significant risk of carbon leakage" and all others; and b) on the application of emission efficiency benchmarks ${ }^{2}$. The recent reform for Phase IV, while not revolutionising free allocation, has introduced some relevant changes.

\subsection{Phase I (2005-2007) and Phase II (2008-2012)}

In the first two trading periods, determining the total volume of allowances and their allocation was the responsibility of national governments. These had to specify their allocation decisions in so-called National Allocation Plans (NAPs), which would enter into force at the end of a reviewing process directed by the European Commission. The purpose of this process was to ensure that final NAPs would meet the criteria set out in the ETS Directive (European Parliament and Council, 2003).

Concerning allocation rules, the ETS Directive imposed two fundamental limits. First, governments could auction up to $5 \%$ and $10 \%$ of the total number of allowances in Phase I and Phase II, respectively. Accordingly, the vast majority of the allowances were given away for free. In fact, many countries decided not to auction any allowances at all. Second, the ETS Directive did not allow ex-post adjustments to initial allocations, as these could have induced strategic behaviour affecting the allowance market.

In general, within the boundaries of the ETS Directive, room was left for discretionary choices by member states. This meant that allocation rules, while largely harmonised, inevitably presented some heterogeneity across countries (Kettner et al., 2008). An example in point is that the ETS Directive did not specify how allocation for new installations or for closing installations had to be regulated. Almost all member states opted for different newentrant and closure provisions, as they are called, whereby new installations are granted free allowances and closing installations forfeit theirs. These rules were much debated at the time because they could distort investment decisions, thus affecting the cost-effectiveness of the EU ETS over the long term (see, e.g., Åhman et al., 2007, and Ellerman, 2008). Moreover, their

\footnotetext{
${ }^{2}$ With benchmarking, an emission rate that characterises emission-efficient production is used as the basis for allocations, with appropriate adjustments for the installation's past or expected production levels.
} 
heterogeneity across countries could distort competition within the European market (Ellerman et al., 2010).

\subsection{Phase III (2013-2020)}

In 2009, a new Directive was agreed (European Parliament and Council, 2009) reforming the EU ETS with effect from Phase III. The overarching institutional innovation was the centralisation of the system. The total volume of allowances - the cap - is now determined at the EU level and a single set of rules governs their allocation. In Phase III, the cap decreases each year by a linear factor of $1.74 \%$ compared to 2010 (the midpoint of 2008-2012), reaching in 2020 a level $21 \%$ below 2005 emissions. At the same time, the allocation regime was radically changed. While very limited in the first two trading periods, auctioning has become the default allocation method for electricity generating installations ${ }^{3}$. For all other installations, benchmarked allocation was introduced.

The application of emission efficiency benchmarks is combined with the identification of the sectors at risk of carbon leakage. Installations in the sectors deemed at significant risk of carbon leakage are given free allowances covering $100 \%$ of their benchmarked emissions. The level of benchmarked emissions is determined by multiplying the relevant benchmark by the installation's recent output level ${ }^{4}$. As a rule, the benchmark corresponds to the average performance of the $10 \%$ most efficient installations over 2007-2008. The European Commission developed 52 product-specific benchmarks and two "fallback approaches" based on heat and fuel consumption (European Commission, 2011). For the installations not falling in a sector at risk of carbon leakage, free allocation is less generous. For them, free allowances cover progressively smaller shares of benchmarked emissions: from $80 \%$ in 2013 to as little as $30 \%$ in 2020 .

The identification of the sectors at risk of carbon leakage is based on two indicators (4digit $\mathrm{NACE}^{5}$ ) computed at the EU level: Carbon (cost) Intensity (CI) and Trade Intensity (TI).

\footnotetext{
${ }^{3}$ By derogation, some member states, among those with a GDP per capita below $50 \%$ of the EU average, can continue free allocation to installations generating electricity in exchange for their modernisation of the sector and for the diversification of the energy mix. In addition, the 2009 ETS Directive introduces a redistribution mechanism operating through cross-country allocation of the allowances to be auctioned. $88 \%$ of these are allocated to member states in proportion to their emission volumes in year $2005.10 \%$ are distributed to the least wealthy member states as an additional source of revenue to help them invest in climate change mitigation and adaptation. The remaining $2 \%$ are given as a bonus to member states which, by 2005 , had reduced their emissions by at least $20 \%$, compared to their base year under the Kyoto Protocol.

${ }^{4}$ In Phase III, this level is the highest between median production over 2005-2008 and median production over 2009-2010.

${ }^{5} \mathrm{NACE}$ is the statistical classification of economic activities in the EU.
} 
CI measures the potential significance of carbon costs as in the maximum impact that carbon prices could have on the sector. CI is given by the ratio of $a$ ) the sum of direct and indirect emissions $^{6}$, valued at $€ 30 / \mathrm{tCO}_{2}$, to $b$ ) the gross value added. TI, which measures the openness of the sector to international competition, is a proxy for the inability to pass through additional costs without loss in international market share. It is defined as the ratio between $a$ ) the total value of exports and imports (to- and from non-EU countries) and $b$ ) the total EU market size, which is equal to the sum of turnover and imports (European Commission, 2009). A sector is then classified as being at risk if one or more of the three following thresholds is exceeded: CI $>30 \%$; TI $>30 \%$; and the double threshold CI $>5 \%$ \& TI $>10 \%$. The first "carbon leakage list" was defined in 2009, for the years 2013 and 2014. Out of 258 sectors, 165 were classified as being at risk. The second list was defined in 2014 for the years 2015-2019.

Because the aggregate amount of preliminary free allocation calculated by member states exceeded the maximum amount of allocation available, a uniform cross-sectoral correction factor (CSCF) has been applied to all installations. In 2013, the CSCF reduced the total number of free allowances by 5.7\% (European Commission, 2013). Since the cap declines over time, the CSCF increases with it, reaching $17.6 \%$ in 2020. The CSCF mechanism has proved contentious because it implies that even the most efficient installations do not receive enough free allowances to cover $100 \%$ of their initial emissions ${ }^{7}$.

\subsection{Phase IV (2021-2030)}

In March 2018, the reform for Phase IV became law after over two years of negotiations (European Parliament and Council, 2018). The reform has three main objectives: strengthening the price signal by reducing the cap at a faster pace ${ }^{8,9}$, better-targeting free allocation, and supporting low-carbon innovation and energy sector modernisation (in lower-income member states) through dedicated funding mechanisms based on auction revenues (the Innovation Fund and the Modernisation Fund).

Focusing on free allocation, the main new provisions are the following. First, as a rule, a sector will be classified as being at risk of carbon leakage if the product of the carbon emissions

\footnotetext{
${ }^{6}$ Indirect emissions are those resulting from the generation of purchased electricity consumed by the entity.

${ }^{7}$ The formula of free allocation in Phase III is reported in the Appendix.

${ }^{8}$ The linear reduction factor applied in Phase IV will be $2.2 \%$. The cap reaches in 2030 a level $43 \%$ below 2005 emissions. This level is consistent with the EU's mitigation target for 2030 (40\% reduction of overall GHG emissions below 1900 levels) set in the 2030 Climate and Energy Framework.

${ }^{9}$ The strengthening of the price signal is also pursued through the enhancement of the Market Stability Reserve mechanism. For an analysis of how changes in different key parameters of allowance supply would impact on allowance price paths in Phase IV and beyond, see Perino and Willner (2017).
} 
intensity indicator (CeI) (expressed in terms of $\mathrm{KgCO}_{2}$ per Euro of gross value added) and the TI indicator, $\mathrm{CeI} \times T I$, exceeds 0.2 . As this rule is more stringent than the one applied in Phase III, the number of sectors classified as being at risk will shrink ${ }^{10}$. Second, to better align allocations with actual production levels, allocations will be adjusted in case of output variations exceeding $+15 \%$ (increases) or $-15 \%$ (decreases) $)^{11}$. Third, to limit the use of the CSCF (if needed), the share of allowances to be auctioned will be reduced instead of applying the $\mathrm{CSCF}$, by up to $3 \%$ of the total quantity of allowances. Other rules relevant to free allocation have not significantly changed from Phase III.

\section{Empirical literature on free allocation rules}

This section provides a comprehensive review of the empirical literature analysing free allocation rules in the EU ETS. The works found (12) are grouped as follows. Four studies focus on the rule used in Phase III for identifying the sectors at risk of carbon leakage. Two studies look at benchmarking: one showing its distributional merits compared to grandfathering, the other pointing to its limitations. Three studies test for whether allocation endowments affected firms' operational decisions. Finally, three papers investigate whether ex-post allocation adjustments, related to closing installations or to major output reductions, induced strategic behaviour.

\subsection{Identification of the sectors at risk of carbon leakage}

As of Phase III, a key free allocation rule is the one determining which sectors are to be considered at risk of carbon leakage. As previously explained, the rule involves the exceeding of at least one of three thresholds: for carbon intensity (CI), for trade intensity (TI), and for both CI and TI considered simultaneously. Four empirical studies were found assessing this rule. The studies are concordant in indicating that the rule is too lenient. That is, it results in too many sectors being classified as being at risk of carbon leakage, some of which are in fact most likely not at risk.

The study by de Bruyn et al. (2013) is chronologically the first. In 2009, the European Commission compiled the first carbon leakage list. It comprised over $60 \%$ of all regulated sectors, representing about $95 \%$ of industrial emissions. Using the same data and methodology

\footnotetext{
${ }^{10}$ According to the European Commission, of the 177 sectors currently classified as at risk, only about 50 will continue to be classified as such. However, the reduction in terms of emissions is smaller than the reduction in terms of sectors (European Commission, 2015).

${ }^{11}$ Variations are relative to production levels considered for determining initial allocations. They are calculated as rolling two-year averages.
} 
of the European Commission, the authors find that the number of sectors classified as being at risk would shrink by $50 \%$ if the calculations were updated to reflect the new economic context. In terms of emissions, the difference would be even bigger, as free allocation would only cover $10 \%$ of industrial emissions. Specifically, two parameters are revised. First, the authors assume an average carbon price, for Phase III, of $€ 12 / \mathrm{tCO}_{2}$, instead of $€ 30 / \mathrm{tCO}_{2}$. Second, they assume benchmarked allocation to cover $80 \%$ of emissions from the sectors deemed at significant risk, instead of $40 \%$. In addition, sectoral TI indicators are recalculated excluding the trade flows between the EU and the countries that, in the meantime, joined the EU ETS.

Using the responses from interviews with more than 400 managers of regulated firms in six European countries ${ }^{12}$, Martin et al. (2014a) measure firm vulnerability to carbon leakage. On a five-point scale, the vulnerability indicator measures managers' expected risk of closing or relocating the firm outside the EU because of carbon pricing. The results indicate this risk to be generally low ${ }^{13}$. The study makes the important point that free allocation is efficient if it equalises, across firms, the marginal propensity to relocate weighted by the relocation damage. The damage could be the displacement of emissions or jobs, or a combination of the two, overseas. The problem is that firms' propensity to relocate is not publicly observable and, if self-stated, it could be manipulated. Yet, the authors demonstrate through simulations that simple allocation rules based on observable firm-level variables, such as emissions and the number of employees, can be more efficient than the allocation system in force.

Martin et al. (2014b) explore the correlations between the same indicator of carbon leakage vulnerability used in Martin et al. (2014a), and both the CI and the TI indicators used by the European Commission. Self-stated relocation risk is found to be strongly correlated with CI but not with TI. Yet, most sectors are classified as being at risk exclusively because TI is high. Thus, two changes to the official rule are proposed. First, sectors with high TI should qualify as being at risk only if CI is high too. Second, in the calculation of TI, only trade with less developed countries, rather than with all non-EU countries, should be considered. If these criteria were applied, the number of sectors classified as being at risk would halve.

Using national statistics for Germany and the UK, Sato et al. (2015) show the significance of variation both in sectoral CI and TI across countries and, therefore, the inefficiency of EU-aggregate CI and TI indicators in identifying sectors at risk at the national

\footnotetext{
12 The interviews were carried out in 2009.

${ }^{13}$ The sectors that are the most vulnerable are: other minerals, glass, iron and steel, and cement, the respective mean values of the vulnerability indicator ranging between 2.5 and 3.5. Other sectors, such as food and tobacco, fabricated metals, and vehicles, are significantly less vulnerable than the average.
} 
level. Cross-country variation in CI is due to differences in production processes, technologies and fuel $\mathrm{mix}^{14}$, as well as in sector classifications and data quality. Sectoral TIs are also shown to vary considerably across countries. TI is also criticised for being a highly imperfect proxy for cost pass-through inability. The authors recommend that measures addressing carbon leakage should be more focused, targeting narrower subsectors. While such measures would remain homogenous in the EU, more factors should be considered for assessing carbon leakage risk at a less aggregate level.

\subsection{Benchmarking}

As of Phase III, emission efficiency benchmarks are applied for determining initial allocations. The main purpose of benchmarking is to give regulated firms an additional incentive for reducing emissions. However, while studies estimating the effect of benchmarking on emission abatement still do not exist - as far as we are aware -, the two summarised below analyse the impact of benchmarking on how well-targeted allocations are.

Sartor et al. (2015) investigate the efficiency and distributional implications of free allocation in Phase III in a comparison with the previous trading periods. The study offers three main results. First, it is estimated that the application of benchmarks alone reduced the total quantity of free allowances by about $20 \%$ relative to Phase II while still sufficiently shielding regulated industries from the risk of carbon leakage. Second, following the switch to the new allocation regime, the redistribution of free allowances across sectors has been small between countries and much more significant within countries. Third, this redistribution within countries represents an efficiency improvement, as the authors show that, before, significant shares of the allocations to installations producing cement were not explained by historical emissions. The conclusion is that free allocation clearly improved, both with respect to efficiency and equity, thanks to the harmonisation of the rules and the introduction of benchmarking.

Stenqvist and Åhman (2016) focus on the adequacy of different benchmarks, showing how well-suited benchmarks are for homogeneous sectors, but significantly less so for highly heterogeneous ones. The allocation results of the application of the benchmarks are compared for the cement industry and for the pulp and paper industry in three countries, namely Sweden, France and the UK. In Europe, while the cement sector is highly homogeneous, the pulp and

\footnotetext{
14 The authors also indicate more specific factors, including cross-country sectoral differences in process emissions, recycling rate and product mix.
} 
paper sector is highly heterogeneous with respect to products, infrastructures and fuel mixes. In this sector, the use of benchmarks biased towards a fossil fuel-mix and based on energy use, rather than on emission intensity, leads to allocations that do not necessarily represent the average performance of the top 10\% emission-efficient installations. Sweden's pulp and paper sector provides a striking example, as the imperfections of the benchmarking system result in significantly higher allocations than in Phase II.

\subsection{Endowment effect}

In the cap-and-trade literature, the endowment effect refers to a situation in which free allocations affect production decisions. The endowment effect is usually explained with firms undervaluing (not fully internalising) the opportunity cost of using free allowances for compliance. Its presence indicates a loss in cost-effectiveness. We have found three studies specifically devoted to testing for the presence of an endowment effect in the EU ETS.

Reguant and Ellerman (2008) exploit a non-linearity in the allocation rule for coal plants in Spain, in Phase I, to test for the relevance of initial allocations to emission abatement outcomes. The evidence suggests no systematic relationship between the initial endowment and production decisions. Zaklan (2016) investigates the same question. Exploiting time and cross-country differences in allocation rules, he tests whether, with Phase III, the switch from free allocation to auctioning affected emissions from electricity-producing installations. No evidence of an endowment effect is found save for a subsample of small emitters. The author also argues that endowment effects are more likely to occur for manufacturing installations, especially small ones, as they tend to be less active traders than electricity producers. This conjecture finds support in the analysis by De Vivo and Marin (2018), who test for whether granting more generous allocations to the installations in sectors classified as being at risk of carbon leakage affected their emission abatement behaviour. It turns out that indeed these installations appear to have reduced emissions less than other regulated manufacturing installations. The authors also suggest that exposure to international competition in manufacturing sectors means that some firms may prefer not to fully pass through opportunity costs.

\subsection{Closure provisions and activity level thresholds}


In the EU ETS, closing installations forfeit their allowance endowments, because - this is the rationale - they no longer need them ${ }^{15}$. The issue with this arrangement is that incentivises delay in the closure of uneconomic installations. Delayed closures imply that windfall profits have accumulated. Precisely to prevent delayed closures and, more generally, to reduce windfall profits in cases of major output reductions, since Phase III allocations are adjusted expost on the basis of activity level thresholds. Three studies analyse the unintended effects of closure provisions and of activity level thresholds.

Verde et al. (2018) show that installation exits from the EU ETS (due to closure or partial closure) were concentrated in the final years of Phases I and II (2007 and 2012). As closure provisions create an incentive to delay exit, the authors investigate whether they explain at least in part the observed pattern of installation exits. A hazard model for the risk of exit is estimated, controlling for several installation and firm-level variables, as well as for higher-level factors. On average, estimated risk evolves differently depending on whether an installation receives free allowances. Strong evidence of the delay effect is found, as only for installations receiving free allowances is the risk of exit time-dependent, steeply increasing the final year of a trading period, especially Phase II.

As of Phase III, to reduce windfall profits of low-activity installations, those whose output falls below $50 \%, 25 \%$, or $10 \%$ of the historical level, see their allocations reduced by $50 \%, 75 \%$ and $100 \%$, respectively. However, producers may respond to these thresholds by increasing output strategically. Comparing emissions in the cement sector before and after the thresholds were introduced, Neuhoff et al. (2014) point to this type of strategic behaviour. Interviews with managers confirm their hypothesis. Branger et al. (2015) extend the analysis and estimate that, in 2012, the activity level thresholds induced excess cement clinker production of 6.4 million tonnes (5\% of total EU output). This resulted in distorted trade patterns and, in some cases (notably Spain's and Greece's), reversals of carbon intensity improvements.

\section{Literature on cost pass-through rates}

In economics, the usual measure of cost pass-through is the Pass-Through Rate (PTR), which quantifies the change in output prices relative to a given cost shock. The PTR is expressed in percentage terms, so that, for example, a carbon cost PTR of $85 \%$ indicates that a $€ 1$ increase

\footnotetext{
${ }^{15}$ In the first two trading periods, defining free allocation rules for new and closing installations was the responsibility of member states. Most if not all member states except Sweden, adopted closure provisions conditioning free allocation on continued production activity (Verde et al., 2018).
} 
in carbon prices results in a $€ 0.85$ increase in output prices. We have identified 20 econometric studies providing sectoral estimates of PTRs for the costs imposed by the EU ETS. The majority of these studies derive PTR estimates for the electricity sector using data from Phases I or II, or both. In the following, the results of this literature are illustrated. The first half of the review covers the studies providing PTR estimates for the electricity sector. The second covers those relevant to regulated manufacturing sectors.

\subsection{Electricity sector}

The prevalence of studies for the electricity sector is explained by data availability and quality as well as by an interest in quantifying potentially large windfall profits, given the combination of expected high PTRs and free allocation in the first two trading periods. Not least, electricity prices are a central variable of the economic system, as electricity is a basic production input and a basic consumption good.

The empirical literature shows that, in Phases I and II, the opportunity costs of free allowances granted to electricity producers were largely passed through to output prices. Two features of electricity markets explain why this could happen: the very limited exposure of producers to international competition and the very low elasticity of electricity demand. There is thus ample evidence that electricity producers were able to profit from regulation. Keppler and Cruciani (2010) estimate that, during Phase I, €19 billion windfall profits per year accrued to the European electricity sector.

Table 1 reports the results of the literature at hand. While being generally high, estimated PTRs exhibit significant variation. Different factors are behind this. First, different econometric techniques are used. Single Equation Models (SEMs) and, within the framework of cointegration, Vector Error Correction Models (VECMs) are the two most popular approaches. Except for Honkatukia et al. (2006), estimated PTRs from VECMs tend to be lower compared to those derived from SEMs ${ }^{16}$. Second, different energy mixes, in different countries, can determine different PTRs. These will be higher if, at the margin of the supply curve, commonly referred to as the "merit order", electricity prices are set by plants using more carbon intensive technologies. Third, since which plant sets the market price also depends on the demand level,

\footnotetext{
${ }^{16}$ VECMs are supposed to be more accurate than SEMs because they control for dynamic interactions among all the independent variables. A second technical distinction can be made between the studies using electricity forward prices (typically, one-year ahead) and those using spot prices (one-day ahead). The choice of which prices to use for estimation is not neutral. On the one hand, spot prices are more volatile, less driven by fuel or carbon costs and more influenced by unforeseen events such as plant outages or weather shocks. On the other hand, greater data variation is useful for parameter identification (Hintermann, 2016).
} 
most studies distinguish between peak hours and off-peak hours. Given the merit order curve, cost pass-through tends to be higher during peak hours. Also, for some producers, bidding below marginal cost may be convenient to avoid switching off plants only for a few hours (Fabra and Reguant, 2014). Fourth, both market power and excess generation capacity matter (Chernyavs'ka and Gullì, 2008). The more concentrated the market is, the higher pass-through is likely to be. Conversely, the more extra capacity is available, the lower pass-through is likely to be.

Table 1. Estimates of carbon cost PTRs for the electricity sector

\begin{tabular}{|c|c|c|c|c|c|c|c|}
\hline Study & Period & Country & $\begin{array}{l}\text { Electricity } \\
\text { price } \\
\text { (spot/forward) }\end{array}$ & Approach & $\begin{array}{l}\text { Average } \\
\text { PTR }\end{array}$ & $\begin{array}{l}\text { Peak } \\
\text { PTR }\end{array}$ & Off-peak PTR \\
\hline Sijm et al. (2006) & 2005 & $\mathrm{DE}, \mathrm{NE}$ & $\mathrm{F}$ & SEM & - & $\begin{array}{l}117 \% \\
78 \%(\mathrm{NE})\end{array}$ & $\begin{array}{ll}60 \% & \text { (DE) } \\
80 \%(\mathrm{NE}) & \end{array}$ \\
\hline $\begin{array}{l}\text { Honkatukia et al. } \\
\text { (2006) }\end{array}$ & $2005-2006$ & $\mathrm{FI}$ & S & VECM & $75-95 \%$ & - & - \\
\hline $\begin{array}{l}\text { Fezzi and Bunn } \\
(2009)\end{array}$ & $2005-2006$ & UK & $S$ & VECM & $32 \%$ & - & - \\
\hline Sijm et al. (2008) & $2005-2006$ & $\begin{array}{l}\text { FR, DE, IT, PO, } \\
\text { ES,SW, CZ, NE, } \\
\text { UK }\end{array}$ & $S$ and $F$ & SEM & $\begin{array}{l}38-134 \% \quad(F), \quad 0- \\
200 \%(S)\end{array}$ & - & - \\
\hline $\begin{array}{l}\text { Fabra and } \\
\text { Reguant (2014) }\end{array}$ & $2005-2006$ & ES & $S$ & SEM & $86 \%$ & $100 \%$ & $60 \%$ \\
\hline $\begin{array}{l}\text { Zachmann and } \\
\text { Hirschhausen } \\
\text { (2008) }\end{array}$ & $2005-2006$ & $\mathrm{DE}$ & $\mathrm{F}$ & VECM & Asymmetric PTR & - & - \\
\hline $\begin{array}{l}\text { Chernyavs'ka } \\
\text { and Gulli (2008) }\end{array}$ & $2005-2007$ & IT & $S$ & Other* & - & $\begin{array}{l}>100 \% \text { if scarcity } \\
\text { of capacity }\end{array}$ & $100 \%$ \\
\hline Fell (2010) & $2005-2008$ & SW,FI, DN, NO & $S$ & VECM & - & $40-70 \%$ & $60-95 \%$ \\
\hline Thoenes (2014) & $2008-2010$ & $\mathrm{DE}$ & $S$ & VECM & $36 \%$ & - & - \\
\hline $\begin{array}{l}\text { Jouvet and Solier } \\
\text { (2013) }\end{array}$ & $2005-2011$ & EU & $S$ and $F$ & SEM & $>100 \%$ & - & - \\
\hline $\begin{array}{l}\text { Freitas and da } \\
\text { Silva (2013) }\end{array}$ & 2008-2011 & PT & $S$ & VECM & $51 \%$ & - & - \\
\hline $\begin{array}{l}\text { Hintermann } \\
(2016)\end{array}$ & $2010-2013$ & $\mathrm{DE}$ & $S$ & SEM & & $111 \%$ & $81 \%$ \\
\hline $\begin{array}{l}\text { Huisman } \\
\text { Kilic (2015) }\end{array}$ & $2007-2013$ & UK, DE & $\mathrm{F}$ & Other** & $\begin{array}{l}47-76 \% \text { (UK), } 20- \\
90 \% \text { (DE) }\end{array}$ & - & - \\
\hline $\begin{array}{l}\text { Freitas and da } \\
\text { Silva (2015) }\end{array}$ & $2008-2013$ & ES & $S$ & VECM & - & $24 \%$ & $25 \%$ \\
\hline
\end{tabular}

Note: * Load duration curve; ${ }^{* *}$ Kalman filter approach.

\subsection{Manufacturing sectors}

Compared to the electricity sector, cost pass-through in manufacturing sectors is much more difficult to analyse. This is firstly because price information for manufacturing products and 
for their inputs may well not be available or sufficient. Secondly, product heterogeneity implies that, within a sector, market conditions relevant to cost pass-through, such as the degree of international competition, the degree of internal market concentration, transportation costs and spare production capacity, can be very diverse (de Bruyn et al., 2015). Thirdly, some of these conditions may vary across countries and, in international markets, the position of a country along the supply curve may matter too. For these reasons, PTR estimates both are few relative to the number of regulated sectors and can be highly variable across countries.

As far as the methodology is concerned, while all the studies reviewed use the cointegration framework, two approaches can be distinguished with respect to the identification strategy. With the cost-price approach, which is the standard one (by far the most common), the product's price is explained by the prices of its input components (e.g., labour, capital, energy, materials) and by carbon prices. De Bruyn et al. (2010a, 2010b) introduce the marketequilibrium approach. This approach rests on the assumption that markets are internationally integrated, to the extent that an equilibrium relationship exists between domestic and foreign prices. In the typical model, the (domestic) EU price of the given product is explained by the corresponding US price, the carbon price and the exchange rate. The attractive aspect of the market-equilibrium approach is information parsimony. Its potential weakness, on the other hand, are the assumptions regarding market integration and price adjustments.

Table 2. Estimates of carbon/energy cost PTRs for manufacturing sectors

\begin{tabular}{|c|c|c|c|c|c|c|c|c|}
\hline Study & Approach & Cement & Ceramic & Chemicals & Glass & $\begin{array}{l}\text { Iron and } \\
\text { steel }\end{array}$ & $\begin{array}{l}\text { Pulp and } \\
\text { paper }\end{array}$ & Refining \\
\hline $\begin{array}{l}\text { Alexeeva-Talebi } \\
(2010)[1]\end{array}$ & Cost-price & $100 \%(\mathrm{DE})$ & & $100 \%(\mathrm{DE})$ & $0 \%(D E)$ & & $\begin{array}{l}0-38 \%(\mathrm{DE}) \\
{[9]}\end{array}$ & \\
\hline $\begin{array}{l}\text { Alexeeva-Talebi } \\
\text { (2011) }\end{array}$ & Cost-price & & & & & & & $100 \%(\mathrm{EU})$ \\
\hline $\begin{array}{l}\text { de Bruyn et al. } \\
(2010 a, b)\end{array}$ & $\begin{array}{l}\text { Market- } \\
\text { equilibrium }\end{array}$ & & & $\begin{array}{l}33-100 \% \quad(E U) \\
{[5]}\end{array}$ & & $\begin{array}{l}>100 \% \\
\text { (N.EU) }\end{array}$ & & $>100 \%(\mathrm{DE})$ \\
\hline $\begin{array}{l}\text { de Bruyn et al. } \\
(2015)\end{array}$ & Cost-price & $\begin{array}{l}20 \%(\mathrm{FR}) \\
40 \%(\mathrm{DE}) \\
90-100 \% \\
(\mathrm{CZ}, \mathrm{PL})\end{array}$ & & $\begin{array}{l}0 \% \text { (N.EU, NL), } \\
100 \%(\mathrm{EU}) \\
{[6]}\end{array}$ & $\begin{array}{l}0 \%(\mathrm{ES}, \mathrm{DE}), \\
40 \%(\mathrm{FR}) \\
60 \%-100 \% \\
\text { (IT) }\end{array}$ & $55-100(\mathrm{EU})$ & & $\begin{array}{l}80-100 \% \text { (IT, } \\
\text { BE, FR, DE, } \\
\text { GR) }\end{array}$ \\
\hline $\begin{array}{l}\text { Oberndorfer et al. } \\
\text { (2010) [3] }\end{array}$ & Cost-price & & $\begin{array}{ll}30-100 \% & \text { (UK) } \\
{[4]}\end{array}$ & $\begin{array}{ll}50-100 \% & \text { (EU) } \\
{[7]} & \end{array}$ & $\begin{array}{l}0-25 \%(\mathrm{UK}) \\
{[8]}\end{array}$ & & & $50-75 \%$ (UK) \\
\hline
\end{tabular}


Table 2 reports the PTR estimates found in the literature. Some PTR estimates refer to electricity costs or to other input costs larger than carbon costs ${ }^{17}$. Very high PTRs are observed for some sectors, notably the refinery sector and the iron and steel sector, while lower PTRs are observed both for the pulp and paper sector and for the glass sector. Other sectors exhibit wide PTR ranges. This is especially true for the chemicals sector and for the ceramics sector, within which different products with different market characteristics are analysed. The empirical evidence on cost pass-through is reviewed below sector by sector.

\section{Cement}

Two relevant studies were found for the cement sector. One by Alexeeva-Talebi (2010), for Germany, analyses pass-through of electricity-, materials- and labour costs during Phase I. Producers are found to pass through up to $73 \%$ of cost shocks and $100 \%$ of electricity cost shocks. De Bruyn et al.'s (2015) study covers several European countries during Phases I to III. Depending on data availability, different products are considered, specifically Portland cement (the most common type), total cement (all types of cement) and clinker (a semiprocessed product). For Portland cement, almost full pass-through (90-100\%) of carbon costs is found in Poland and the Czech Republic. By contrast, for total cement, PTRs range from $20 \%$ in France to $40 \%$ in Germany. For clinker, estimated PTRs are around $35-40 \%$. Considering the low transportability of cement, estimated PTRs are perhaps not as high as one might expect (except for Poland's and Czech Republic's results). The authors suggest three possible explanations, which relate to production overcapacity, long-term contracts (in the presence of which empirical models cannot properly capture the effect of carbon prices) and the incentive to increase production associated with activity level thresholds (see Section 3.3 above).

\section{Ceramics}

For the ceramics sector, only one study was found (Oberndorfer et al., 2010). Here, the estimated PTRs refer to energy costs. Pass-through for ceramic goods and ceramic bricks, in the UK, are analysed. While full pass-through (100\%) is found for ceramic goods, a PTR of $30-40 \%$ is estimated for ceramic bricks used in construction. The fundamental differences between the two types of products underlie the different results.

\footnotetext{
${ }^{17}$ Using larger shares of variable costs helps econometric identification of PTRs.
} 


\section{Chemicals}

The chemicals sector comprises many subsectors and products. The literature mainly focuses on two subsectors: petrochemicals and fertilisers. Concerning the first, different types of plastics are considered, notably polyethylene (PE), polystyrene (PS), polyurethane (PUR), polypropylene (PP) and polyvinylchloride (PVC). As to the second, ammonium products and nitrogen compounds are the goods most frequently analysed.

De Bruyn et al. (2015) offer the most comprehensive analysis of cost pass-through for chemicals. The models for the prices of petrochemicals include, as explanatory variables, the naphtha price (naphtha being the main input), the price of emission allowances and other potentially relevant variables, such as energy prices, output and stock indices, wages, interest rates and the euro-dollar exchange rate. The estimated PTRs generally exceed 100\%. The same approach is used for fertilisers, except for the naphtha price being replaced by the natural gas price. PTRs over $100 \%$ are derived for ammonium nitrate (UK), calcium ammonium nitrate (Germany), urea (North Western Europe - NWE) and urea ammonium nitrate (France). By contrast, those for ammonia (NWE) and urea (Netherlands) are not particularly significant. Limited transportability is the main explanation for the very high PTRs in this sector.

The above results are largely consistent with those of previous studies. Using the marketequilibrium approach, de Bruyn et al. (2010a, 2010b) find full pass-through both for PE and PVC. For PS, which has higher carbon content, the resulting PTR is 33\%. In Germany, Alexeeva-Talebi (2010) finds full pass-through of electricity costs for most of the chemical products considered. In the UK, Oberndorfer et al. (2010) find energy cost PTRs of 100\% and $50 \%$ for, respectively, PE and fertilisers.

\section{Glass}

Analyses of cost pass-through for the glass sector are limited by the lack of data. Hollow glass, which makes $50-60 \%$ of the EU's total glass production, is the only type of glass for which multiple PTR estimates exist. Estimates for flat glass (25\% of the European glass production, mainly supplied to the building and automotive industries) were not found. For hollow glass, de Bruyn et al. (2015) find null carbon cost PTRs both for Germany and Spain, a PTR of 40\% for France and one of 60-100\% for Italy. Alexeeva-Talebi (2010) and Oberndorfer et al. (2010) analyse energy costs pass-through, also for hollow glass, in, respectively, Germany and the UK. The first finds null PTR, while the second find a PTR of 0-25\%. Alexeeva-Talebi (2010) also finds non-significant PTRs for fibre glass and for "other processed glasses". 
In general, except for high pass-through found in Italy, the evidence indicates null to low cost pass-through for hollow glass. De Bruyn et al. (2015) relate this result to strong international competition and to market conditions whereby the main input (soda ash) is supplied by a small number of companies and demand is dominated by a few large multinational firms. Furthermore, as carbon cost is a small share of total production costs (about $1 \%$ for hollow glass), pass-through is difficult to detect.

\section{Iron and steel}

Using the market-equilibrium approach, de Bruyn et al. (2010a, 2010b) analyse carbon cost pass-through for hot and cold rolled coil (two representative steel products) in Northern Europe. PTRs over $100 \%$ are found for both products. In a follow-up study, de Bruyn et al. (2015) repeat the analysis using the cost-price model and extending country coverage. For hot rolled coil, PTRs of 75\% and over 100\% are found in Northern Europe and Southern Europe, respectively. For cold rolled coil, estimated PTRs are $85 \%$ and 55\%, in the same order. Different factors underlie this range of high PTRs. On the one hand, transportation costs play a role in limiting imports ${ }^{18}$. On the other, the fall in demand following the economic crisis and expansion of steel production in Asia resulted in lower utilisation rates in Europe's steel production capacity. Under such circumstances, keeping prices competitive becomes even more important, which may explain incomplete PTRs $(<100 \%)$.

\section{Pulp and paper}

Little empirical evidence on cost pass-through in the pulp and paper sector exists. The evidence we have is not specific to carbon costs, which make up less than $1 \%$ of total production costs. Electricity costs are instead significant, as they usually represent about $10 \%$ of total costs. Alexeeva-Talebi (2010) finds that, in Germany, the paper industry can pass-through only a small fraction, if any, of its cost shocks. A maximum cost PTR (taking together the costs of labour, energy and materials) of $38 \%$ is estimated for household and toilet paper, while no pass-through is found for paper and paperboard.

\section{Refining}

\footnotetext{
${ }^{18}$ According to Reinaud (2005), considering transportation costs and assuming full pass-through by European producers, carbon prices would need to be around $€ 28 / \mathrm{tCO}_{2}$ for Chinese steel to compete with marginal steel production in Europe.
} 
Using the market-equilibrium approach, de Bruyn et al. (2010a, 2010b) find carbon cost PTRs in Germany to be over $100 \%$ for petrol, diesel and gasoil. These findings are confirmed by a follow-up study (de Bruyn et al., 2015), which uses the cost-price approach. Only slightly lower PTRs, ranging from $80 \%$ to $100 \%$, are found for petrol in Belgium, France, Germany and Italy. Looking at 14 European countries, Alexeeva-Talebi (2011) also finds extensive evidence for full pass-through of carbon costs. In the UK, Oberndorfer (2010) estimates lower PTRs of $75 \%$ and $50 \%$ for, respectively, petrol and diesel.

The two cross-country studies, namely Alexeeva-Talebi (2011) and de Bruyn et al. (2015), stress the roles of low demand price elasticities and of heterogeneous emission intensities. Both unresponsive demands and the small weight of carbon in total fuel production costs (about 2\%) explain high PTRs. However, these may be reinforced by differences across countries in emission intensities: if the plant setting the price passes through $100 \%$ of its carbon costs, more efficient plants can increase profits by passing through more than $100 \%$ of their carbon costs.

\section{Concluding remarks}

In the history of the EU ETS, Phase III represents a turning point with respect to how emission allowances are allocated: the principle of "free-allocation as the norm and auctioning as an option" was replaced by "auctioning as the default and free allocation as the exception". This change reflected the political will to address the equity issue of large windfall profits accruing to firms in certain sectors, notably the electricity sector, at the expense of the general public in the form of foregone fiscal revenues. However, because the EU ETS also covers manufacturing sectors exposed to international competition, targeted free allocation remained necessary for safeguarding their competitiveness and, thereby, for minimising the risk of carbon leakage. The ultimate purpose of the rule for identifying the sectors at risk of carbon leakage is indeed to preserve the environmental effectiveness of the system, and to do it efficiently. The application of emission efficiency benchmarks was the second major innovation concerning allowance allocation brought in with Phase III. Benchmarked allocation is potentially very important because it provides additional incentives to abate emissions.

The new or amended free allocation rules defined in the reform for Phase IV can be expected to further improve the efficiency of the allocation system. First, the rule for identifying the sectors at risk of carbon leakage will more efficiently identify such sectors by considering carbon emissions intensity (CeI) and trade intensity (TI) simultaneously. Second, the incentives to abate emissions offered by the benchmarking system should be strengthened 
thanks to the more limited application of the CSCF (albeit with the "concession" of letting the volume of free allocation expand). Third, allocations will adjust dynamically for output variations exceeding $+/-15 \%$. This means that fast-growing installations will face more limited increases of carbon costs. At the same time, the rule will allow reduction of windfall profits accruing to installations with shrinking output.

The difficulty of accurately quantifying differences in cost pass-through ability, especially in manufacturing sectors (due to limited data availability and market heterogeneity), is clearly the main obstacle to achieving further efficiency in allowance allocation. The TI indicator is an imperfect proxy for cost pass-through (in)ability, which - as we have seen depends on product- and location-specific characteristics of the market. The reform for Phase IV does in fact make progress in the direction of a) considering the CeI and TI indicators for narrower subsectors, and $b$ ) considering complementary qualitative assessments of abatement potential, market characteristics and profit margins. However, this improvement in the evaluation of cost pass-through ability (more precise and comprehensive as it is) can only result in the addition of sectors or subsectors to the carbon leakage list, not in their cancellation from it.

Finally, with carbon prices expected to rise and the total volume of allowances shrinking, free allocation - however efficient may it be - cannot be the only or main measure for preventing carbon leakage in the future. There is, so far, no empirical evidence of significant negative effects of the EU ETS on the competitiveness of regulated sectors (Verde, 2018; Joltreau and Sommerfeld, 2018). However, today, accompanying free allocation with effective support to low-carbon innovation is more important than ever. Action has been taken in this respect through the Innovation Fund and the Modernisation Fund established under the last reform. For the longer term, reducing carbon price differentials across countries is also paramount. Rather than venturing down the controversial road of border carbon price adjustments, the EU is already engaged in international carbon market cooperation that certainly can serve this goal well.

\section{References}

Åhman, M., Burtraw, D., Kruger, J. and L. Zetterberg (2007), A ten-year rule to guide allocation of EU emission allowances, Energy Policy, 35(3), 1718-1730. 
Alexeeva-Talebi, V. (2010), Cost pass-through in strategic oligopoly: sectoral evidence for the EU ETS, Discussion Paper 10-056, Centre for European Economic Research (ZEW), Mannheim, Germany.

Alexeeva-Talebi, V. (2011), Cost pass-through of the EU emissions allowances: examining the European petroleum markets, Energy Economics, 33, S75-S83.

Bovenberg, A.L. and L.H. Goulder (2000), Neutralising the adverse industry impacts of $\mathrm{CO}_{2}$ abatement policies: what does it cost?, Resources for the Future Discussion Paper 00-27.

Branger, F., Ponssard, J.P., Sartor, O. and M. Sato (2015), EU ETS, free allocations, and activity level thresholds: the devil lies in the details, Journal of the Association of Environmental and Resource Economists, 2(3), 401-437.

Chernyavs'ka, L. and F. Gullì (2008), Marginal $\mathrm{CO}_{2}$ cost pass-through under imperfect competition in power markets, Ecological Economics, 68(1-2), 408-421.

Coase, R.H. (1960), The problem of social cost, Journal of Social Economics, 3, 1-44.

de Bruyn, S., Markowska, A., de Jong, F. and M. Bles (2010a), Does the energy intensive industry obtain windfall profits through the EU ETS?, Delft, CE Delft.

de Bruyn, S., Markowska, A. and D. Nelissen (2010b), Will the energy-intensive industry profit from EU ETS under Phase 3?, Delft, CE Delft.

de Bruyn, S., Nelissen, D. and M. Koopman (2013), Carbon leakage and the future of the EU ETS market - Impact of recent developments in the EU ETS on the list of sectors deemed to be exposed to carbon leakage, Delft, CE Delft.

de Bruyn, S., Vergeer, R., Schep, E.,'t Hoen, M., Korteland, M., Cludius, J., Schumacher, K., Zell-Ziegler, C. and S. Healy (2015), Ex-post investigation of cost pass-through in the EU ETS - An analysis for six sectors, Report for the European Commission, CE Delft and Oeko-Institut.

de Bruyn, S., Schep, E., Cherif, S. and T. Huigen (2016), Calculation of additional profits of sectors and firms from the EU ETS 2008-2015, Delft, CE Delft.

De Vivo, N. and G. Marin (2018), How neutral is the choice of the allocation mechanism in cap-and-trade schemes? Evidence from the EU ETS, Argomenti, 9, 21-44.

Ellerman, D. (2008), New entrant and closure provisions: how do they distort?, The Energy Journal, 29, 63-76.

Ellerman, D., Convery, F. and C. de Perthuis (2010), Pricing carbon - The European Union Emissions Trading Scheme, Cambridge University Press.

European Commission (2009), Impact assessment accompanying the Commission Decision determining a list of sectors and subsectors which are deemed to be exposed to a significant risk of carbon leakage pursuant to Article 10a (13) of Directive 2003/87/EC, Staff Working Paper, Brussels, European Commission. 
European Commission (2011), Decision 2011/278/EU on determining Union-wide rules for harmonised free emission allowances pursuant to Article 10a of Directive 2003/87/EC of the European Parliament and of the Council, Brussels, European Commission.

European Commission (2013), Decision 2013/448/EU concerning national implementation measures for the transitional free allocation of greenhouse gas emission allowances in accordance with Article 11(3) of Directive 2003/87/EC of the European Parliament and of the Council, Brussels, European Commission.

European Commission (2015), Impact assessment accompanying the document Proposal for a Directive of the European Parliament and of the Council amending Directive 2003/87/EC to enhance cost-effective emission reductions and low-carbon investments, Working document, Brussels, European Commission.

European Parliament and Council (2003), Directive 2003/87/EC of the European Parliament and of the Council of 13 October 2003 establishing a scheme for greenhouse gas emissions trading within the Community and amending Council Directive 96/61/EC, Brussels, European Parliament and Council.

European Parliament and Council (2009), Directive 2009/29/EC of the European Parliament and of the Council of 23 April 2009 amending Directive 2003/87/EC so as to improve and extend the greenhouse gas emission allowance trading scheme of the Community, Brussels, European Parliament and Council.

European Parliament and Council (2018), Directive 2018/410 of the European Parliament and of the Council of 14 March 2018 amending Directive 2003/87/EC to enhance cost-effective emission reductions and low-carbon investments, and Decision (EU) 2015/1814, Brussels, European Parliament and Council.

Fabra, N. and M. Reguant (2014), Pass-through of emissions costs in electricity markets, The American Economic Review, 104(9), 2872-2899.

Fell, H. (2010), EU-ETS and Nordic electricity: a CVAR analysis, The Energy Journal, 31(2), $1-25$.

Fezzi, C. and D.W. Bunn (2009), Structural interactions of European carbon trading and energy prices, The Journal of Energy Markets, 2(4), 53-69.

Freitas, C.J.P. and P.P. da Silva (2013), Evaluation of dynamic pass-through of carbon prices into electricity prices - a cointegrated VECM analysis, International Journal of Public Policy, $9(1-2), 65-85$.

Freitas, C.J.P. and P.P. da Silva (2015), European Union emissions trading scheme impact on the Spanish electricity price during phase II and phase III implementation, Utilities Policy, 33, 54-62.

Hahn, R. W. and R. N. Stavins (2011), The effect of allowance allocations on cap-and-trade system performance, The Journal of Law and Economics, 54, S267-S294. 
Hintermann, B. (2016), Pass-through of $\mathrm{CO}_{2}$ emission costs to hourly electricity prices in Germany, Journal of the Association of Environmental and Resource Economists, 3(4), 857891.

Honkatukia, J., Mälkönen V. and A. Perrels (2006), Impacts of the European Emission Trade System on Finnish wholesale electricity prices, VATT Discussion Paper 405, Government Institute for Economic Research (VATT), Helsinki (Finland).

Huisman, R. and M. Kilic (2015), Time variation in European carbon pass-through rates in electricity futures prices, Energy Policy, 86, 239-249.

Joltreau, E. and K. Sommerfeld (2018), Why does emissions trading under the EU Emissions Trading System (ETS) not affect firms' competitiveness? Empirical findings from the literature, Climate Policy, DOI: 10.1080/14693062.2018.1502145.

Jouvet, P., and B. Solier (2013), An overview of $\mathrm{CO}_{2}$ cost pass-through to electricity prices in Europe, Energy Policy, 61, 1370-1376.

Keppler, J.H. and M. Cruciani (2010), Rents in the European power sector due to carbon trading, Energy Policy, 38(8), 4280-4290.

Kettner, C., Köppl, A., Schleicher, S.P. and G. Thenius (2008), Stringency and distribution in the EU Emissions Trading Scheme: first evidence, Climate Policy, 8, 41-61.

Martin, R., Muûls, M., de Preux, L.B. and U.J. Wagner (2014a), Industry compensation under relocation risk: a firm-level analysis of the EU Emissions Trading Scheme, American Economic Review, 104 (8), 1-25.

Martin, R., Muûls, M., de Preux, L.B. and U.J. Wagner (2014b), On the empirical content of carbon leakage criteria in the EU Emissions Trading Scheme, Ecological Economics, 105, 7888 .

Neuhoff, K., Vanderborght, B., Ancygier, A., Atasoy, A.T., Haussner, M., Ismer, R., Mack, B., Ponssard, J.B., Quirion, P., van Rooij, A., Sabio, N., Sartor, O., Sato, M. and A. Schopp (2014), Carbon control and competitiveness post 2020: the cement report, Climate Strategies.

Oberndorfer, U., Alexeeva-Talebi, V. and A. Löschel (2010), Understanding the competitiveness implications of future phases of EU ETS on the industrial sectors, Discussion Paper 10-044, Centre for European Economic Research (ZEW), Mannheim (Germany).

Perino, G. and M. Willner (2018), EU-ETS Phase IV: allowance prices, design choices and the market stability reserve, Climate Policy, 17(7), 936-946.

Quirion, P. (2003), Allocation of $\mathrm{CO}_{2}$ allowances and competitiveness: a case study on the European iron and steel industry, Mimeo.

Reguant, M. and D. Ellerman (2008), Grandfathering and the endowment effect: an assessment in the context of the Spanish National Allocation Plan, MIT CEEPR Working Paper 08-018. 
Reinaud, J. (2005), Industrial competitiveness under the European Union Emissions Trading Scheme, IEA Information Paper, International Energy Agency, Paris (France).

Sartor, O., Pallière, C. and S. Lecourt (2015), Benchmark-based allocations in EU ETS Phase 3: an early assessment, Climate Policy, 14(4), 507-524.

Sato M., Neuhoff, K., Graichen, V., Schumacher, K. and F. Matthes (2015), Sectors under scrutiny: evaluation of indicators to assess the risk of carbon leakage in the UK and Germany, Environmental and Resource Economics, 60, 99-124.

Sijm, J.P.M., Hers, J.S., Lise, W. and B.J.H.W. Wetzelaer (2008), The impact of the EU ETS on electricity prices, final report to DG Environment of the European Commission. Netherlands.

Sijm, J., Neuhoff, K., and Y. Chen (2006), $\mathrm{CO}_{2}$ cost pass-through and windfall profits in the power sector, Climate Policy, 6(1), 49-72.

Stenqvist, C. and M. Åhman (2016), Free allocation in the 3rd EU ETS period: assessing two manufacturing sectors, Climate Policy, 16(2), 125-144.

Thoenes, S. (2014), Understanding the determinants of electricity prices and the impact of the German nuclear moratorium in 2011, The Energy Journal, 35(4), 61-78.

Verde, S.F. (2018), The impact of the EU Emissions Trading System on competitiveness and carbon leakage, Mimeo.

Verde, S.F., Graf, C., and T. Jong (2018), Installation entries and exits in the EU ETS: patterns and the delay effect of closure provisions, Mimeo.

Volleberg, H.R.J., de Vries, J.L. and P.R. Koutstaal (1997), Hybrid carbon incentive mechanisms and political acceptability, Environmental and Resource Economics, 9, 43-63.

Zachmann, G. and C. von Hirschhausen (2008), First evidence of asymmetric cost passthrough of EU emissions allowances: examining wholesale electricity prices in Germany, Economics Letters, 99(3), 465-469.

Zaklan, A. (2016), Free allocation and the endowment effect in cap-and-trade systems: evidence from the European electricity sector, Beiträge zur Jahrestagung des Vereins für Socialpolitik 2016: Demographischer Wandel - Session: Energy Markets, No. C02-V2.

\section{Appendix}

The following formula operationalises allocation of free allowances in Phase III (European Commission, 2011):

$$
F A_{i, t}=B E N_{i} \times H A L_{i} \times C L C F_{i, t} \times \mathrm{CSCF}_{t}
$$

where: 
- $F A_{i, t}$ is the total free allocation of installation $i$ in year $t$;

- $B E N_{i}$ is the benchmark for installation $i$ which depends on the product emissions intensity based on the average emissions intensity of the $10 \%$ most efficient installations in the EU ETS in 2007-2008;

- $H A L_{i}$ is the historical production level based on the highest value of the median annual production levels over 2005-2008 or 2009-2010;

- $\quad C L C F_{i, t}$ is the linear reduction factor for installation $i$. For the installations which are not at risk of carbon leakage, it goes from $80 \%$ in 2013 to $30 \%$ in 2020; for the installations that are at risk of carbon leakage, it is 1 ;

- $C S C F_{t}$ is the cross-sectoral correction factor to ensure that the total free allocation do not exceed the cap;

- $F A_{i, t}$ is reduced by $50 \%, 75 \%$ or $100 \%$ if the annual level of production falls below $50 \%, 25 \%$ or $10 \%$ of the historical activity level $H A L_{i}$. 